\title{
Reconstruction of Partial Auricular Defects by Polypropylene Mesh Helix Framework
}

\author{
Ayman F. Mehanna \\ General Surgery Department, Division of Plastic Surgery, Faculty of Medicine, Zagazig University Hospitals, Zagazig, Egypt. \\ Email: Aymanfikry73@hotmail.com
}

Received April $4^{\text {th }}, 2012$; revised May $1^{\text {st }}, 2012$; accepted June $4^{\text {th }}, 2012$

\begin{abstract}
Background: Current techniques in partial auricular reconstruction can utilize an autologous or alloplastic framework covered by a variety of soft tissue envelopes. Objective: Is to evaluate the benefit of using polypropylene mesh to reconstruct helix framework in partial auricular defects covered with local postauricular skin flap. Method: Eleven patients with partial auricular defect were treated by using polypropylene mesh helix framework which is covered with post auricular flap in a two stage repair; clinical results of the procedure were evaluated. Results: This technique achieved satisfactory results in 9 (81.8\%) cases. Early Post operative complications: Hematoma formation in one case, mild infection in two cases, edema in two cases, and Partial overlying skin breakdown in one case with failure of technique. Late Post operative complications: Hypertrophic scar in one case, narrow retroauricular sulcus in one case, hair bearing skin over the auricle in one case. Conclusion: It is a simple technique, with satisfactory clinical results, easily done, even under local anesthesia, with no donor site morbidity of autogenous cartilage harvesting, not costly as other alloplastic substitutes, large series and longer follow up period are needed for better evaluation of this technique.
\end{abstract}

Keywords: Partial Auricular Defects; Polypropylene Mesh; Helix Framework Reconstruction

\section{Introduction}

Reconstruction of partial auricular defects represents a unique and complex challenge to the plastic surgeon, due to delicate and complex architecture of the structure of the auricle [1]. Apart from functional importance, the auricle also has a great aesthetic value, because it frames the face and provides symmetry [2]. The helical rim is aesthetically critical because it forms the contours of the ear [3].

A common defect taking place in the ear is marginal loss of the ear frame involving a variable segment of the helix with or without a cartilage defect $[2,4]$. These defects could be the result of traumatic laceration or avulsion injuries, animal or human bites, traffic injuries, burns, and others, may require plastic surgical reconstruction $[3,4]$. The ear is a frequent site of skin tumors, especially those predisposed by sun exposure. Basal cell carcinomas are the most frequent type, then squamous cell carcinomas, melanomas and other tumors [3].

Patients often let their tumors go untreated for a considerable time, so that the primary defects get larger than in other, more eye-catching, areas of the face [3].

The chief problem in ear reconstruction has been to obtain an appropriate substitute for the fibrocartilaginous framework of the normal ear [5]. The auricular defect reconstruction can be done either by autogenous material like costal cartilage or by alloplastic material [6]. Over the years, numerous alloplastic materials have been used to create a framework for use in ear reconstruction [7].

The advantage of using alloplastic material is that it avoids overall the procedure of harvesting costal cartilage. Therefore there is less morbidity of the patient, avoidance of additional scar and the technical difficulties of carving the costal cartilage [8].

The technique presented is the use of polypropylene mesh in partial ear reconstruction; it is a two stage repair with 6 - 8 weeks interval.

\section{Patient and Method}

Between October 2009 and February 2011, 11 patients were underwent partial auricular defect reconstruction by Polypropylene mesh helix frame covered by postauricular skin flap in two stage repair; the included patients were 9 men and 2 women (Table 1), their age was ranging from 16 to 62 years old (Table 2).

There were 6 cases post traumatic injury all in male, and 4 cases post tumor excision (2 females and 2 males), and 1 case with congenital partial helix defect (Table 3).

There were 7 cases involving the upper and middle third of the auricle and 3 cases in the upper third and one 
Table 1. Age characteristics.

\begin{tabular}{cccccc}
\hline Age & N. & Min. & Max. & Mean & $\begin{array}{c}\text { Std. } \\
\text { Deviation }\end{array}$ \\
\hline $\begin{array}{c}\text { Valid N } \\
\text { (Listwise) }\end{array}$ & 11 & 16.00 & 65.00 & 34.3636 & 19.3663 \\
\hline
\end{tabular}

Table 2. Sex characteristics.

\begin{tabular}{cccc}
\hline Sex & Frequency & Percent (\%) & Valid Percent (\%) \\
\hline Male & 9 & 81.8 & 81.8 \\
Female & 2 & 18.2 & 18.2 \\
Total & 11 & 100.0 & 100.0 \\
\hline
\end{tabular}

Table 3. Aetiopathogenesis.

\begin{tabular}{cccc}
\hline Ateiology & Frequency & Percent (\%) & Valid Percent (\%) \\
\hline Congenital defect & 1 & 9.1 & 9.1 \\
Post traumatic & 6 & 54.5 & 54.5 \\
Post tumor & 4 & 36.4 & 36.4 \\
Total & 11 & 100.0 & 100.0 \\
\hline
\end{tabular}

case in the middle third of the auricle, 8 patients were done under local infiltration anesthesia and 3 patients under general anesthesia. Patients were followed up from 2 months to 12 months.

\subsection{Preoperative Planning}

The size and shape of the auricle ear to be reconstructed is planned with the use of a template drown on a sheet of transparent material (e.g., radiographic film) traced from the opposite normal ear.

\subsection{Surgical Procedure}

\subsubsection{The $1^{\text {st }}$ Stage}

After surgical resection of a tumor with adequate safety margin and frozen section histopathology is done, or refreshing of the auricular stump of the ear in case of old or recent trauma is done.

1-Construction of poly propylene helix framework by rolling the mesh on it self to obtain the appropriate girth, then multiple 4 - 0 or 5 - 0 non-absorbable sutures are used to maintain the frame.

2-A subcutaneous pocket is prepared in the normal post auricular skin at the edge of auricular stump, extending $1-1.5 \mathrm{~cm}$ beyond the outlined ear margins. This additional dissection is done to ensure tension free closure and help proper coaptation of skin on the helix framework, then homeostasis is ensured well and the helix framework is sutured to the edges of remaining helix by $4-0$ or 5 - 0 non-absorbable sutures, and the poly propylene helix framework is fixed to the underling fascial layer to keep the frame in its place and preserve the shape of the frame, the overlying skin is tucked by tension sutures to fascial layer around the frame, finally a suction drain is used to help skin coaptation of the framework Figure 1. In case of middle third defect a U shaped post auricular flap is raised and sutured to skin of the stump then coapted well to the framework Figure 2.

\subsubsection{The $2^{\text {nd }}$ Stage}

The $2^{\text {nd }}$ stage was done 6 - 8 weeks after the $1^{\text {st }}$ stage, a skin incision is made $1-1.5 \mathrm{~cm}$ behind the posterior margin of the frame, then the dissection was performed beneath the frame work taking care to preserve a enough connective tissue layer on the frame, until the sufficient amount of projection and creation of retroauricular sulcus

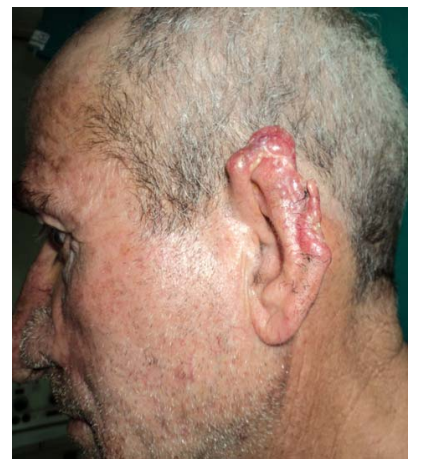

(a)

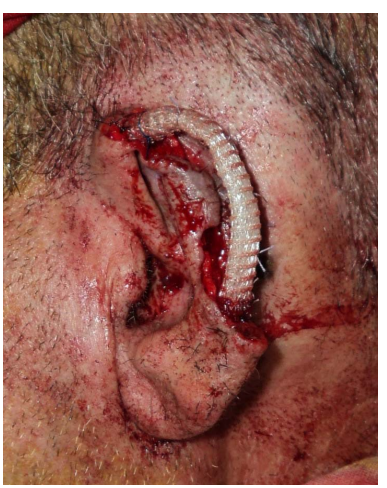

(c)

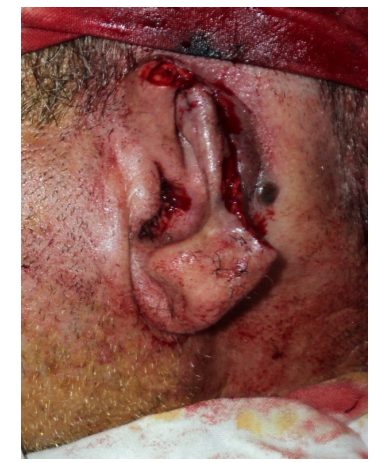

(b)

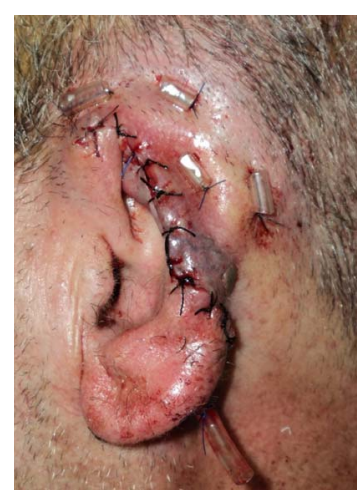

(d)
Figure 1. (a)-(d) First stage of the procedure. (a) Tumor is involving the upper and middle thirds of auricle; (b) Tumor excision with safety margin; (c) Fabricated mesh fixed in its place; (d) Coapted skin over the mesh.

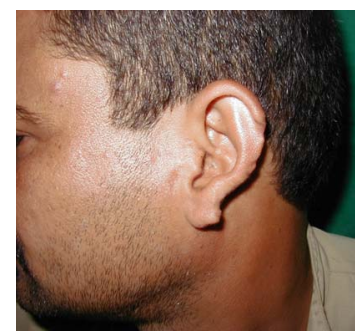

(a)

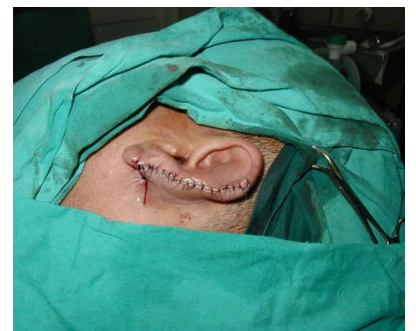

(b)
Figure 2. (a) Traumatic partial auricular loss; (b) U shaped postauricular flap. 
is obtained, the skin of the scalp and mastoid skin is advanced to reduce the defect and fixed in its place, residual defect in the retro auricular plane is covered with a full thickness skin graft Figures $\mathbf{3}$ and $\mathbf{4}$.

\section{Results}

Reconstructed auricles were evaluated in comparison to the normal side according to the following criteria: size, position, shape and contour, and long term stability. The results were satisfactory in 9 (81.8\%) cases.

There were early post-operative complications: Hematoma formation occurred in one case, mild infection in two cases and were treated with i.v. antibiotic, edema occurred in two cases, and Partial overlying skin breakdown in one case that ends with failure of reconstruction (Table 4).

Late Postoperative complications were hypertrophic scar in one case, narrow retroauricular sulcus in one case, and hair bearing skin over the auricle in one case (Table 5).

\section{Discussion}

Accurate reconstruction of the external ear after trauma,

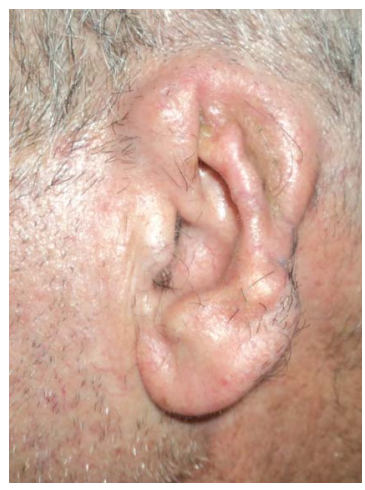

(a)

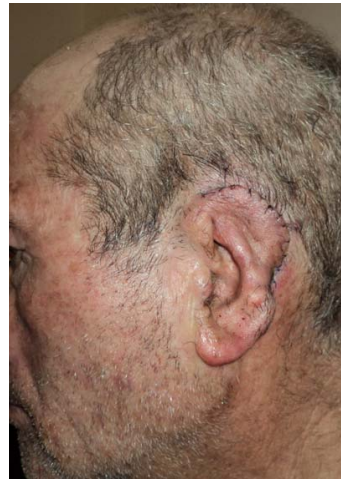

(b)
Figure 3. Second stage of the procedure. (a) 6 weeks after the first stage; (b) Post auricular skin incision and final result.

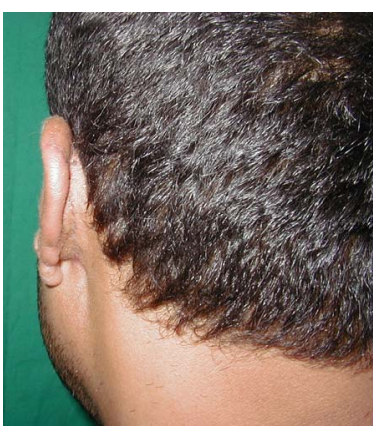

(a)

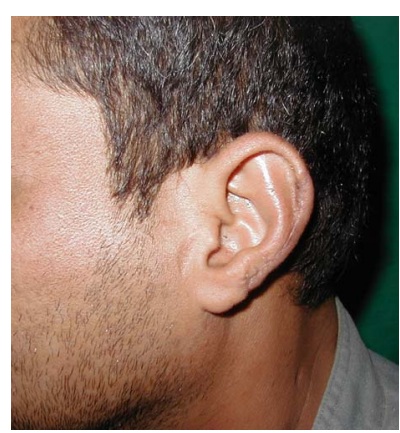

(b)
Figure 4. Second stage of the procedure. (a) Two months after the $2^{\text {nd }}$ stage; (b) Wide retroauricular sulcus.
Table 4. Early post op. complications.

\begin{tabular}{ccc}
\hline Early complications & Frequency & Percent (\%) \\
\hline Edema & 2 & 18.2 \\
Haematoma & 1 & 9.1 \\
Infection & 2 & 18.2 \\
Skin breakdown & 1 & 9.1 \\
Total & 11 & 100.0
\end{tabular}

Table 5. Late post op. complications.

\begin{tabular}{ccc}
\hline Late complications & Frequency & Percent (\%) \\
\hline Hair bearing skin & 1 & 9.1 \\
Hypertrophic scar & 1 & 9.1 \\
Narrow retroauricular sulcus & 1 & 9.1 \\
Total & 11 & 100.0 \\
\hline
\end{tabular}

burn or local excision of tumors is demanding and difficult due to the complex tissue structure of the auricle and also has been a common challenge in plastic surgery [2,9]. The helical rim, the anti-helix fold with its crura, and the concha are structures with highly-elastic stability that prevent collapse of the auricle [3].

Framework fabrication is one of the important steps in ear reconstruction [10]. The use of autogenous rib cartilage framework was first proposed by Tanzer in 1959 [9], then Brent improved techniques and combined the use of expanded postauricular flap with autogenous rib cartilage framework [11].

Over the years, numerous alloplastic materials have been used to create a framework for use in ear reconstruction [7]. Success has likely relates to the surface biocompatibility of the alloplastic material, its pliability, durability, and tendency for tissue adherence [7]. The alloplastic implant has to be easy to shape, strong yet somewhat flexible and is remarkably stable; and it exhibits tissue ingrowth into its pores. It should be highly inert material [12]. Silicone rubber was commonly used throughout the 1960s and 1970s for ear and nasal reconstruction, exhibited a high extrusion rate likely due to its lack of porosity and tissue adherence [13].

Porous polyethylene implant was first described by Berghaus in 1982 [14]. Polyethylene is porous material promotes tissue ingrowth of fibrovascular tissue and adherence, and has proved quite advantageous as a scaffold for ear reconstruction. $[15,16]$, in the current series the polypropylene mesh shows the knitted nature which helps fibrovascular ingrowth.

Wellisz, 1993, proposed the use of $\left(\mathrm{MEDPOR}^{\circledR}\right)$, a medical grade porous polymer material as a helix framework for ear reconstruction in burned ear with excellent results [17]. Sengezer et al., 1996 mentioned that the results were accepted as pleasing by the 10 adult patients 
of ear reconstruction cases were performed by using porous polyethylene implants [18]. Zhao et al. 2009 achieved excellent results in 301 patients (84.8\%) from 355 patients reconstructed by porous polyethylene [9]. In this article we achieve satisfactory results in 9 (81.8\%) from 11 cases.

The Infection of the rib cartilage framework is a severe complication, it difficult to cure with antibiotics [9]. The homogenous costal cartilages and fibrocartilage framework, have mainly failed as a result of infection and absorption [5]. Sengezer et al. 1996 reported one infected case from ten implants was salvaged by irrigation with antibiotics [18]. Zhao et al. 2009 mentioned that the infection was in 8 cases (0.5\%) from 1485 cases underwent autogenous graft framework while was 1 case $(0.2 \%)$ in 355 MEDPOR $^{\circledR}$ alloplastic frame cases [9]. While Wellisz, 1993 reported no cases of infection occurred in 41 patients with porous polyethylene Implants were placed as an ear framework reconstructions [12]. In this article two cases with mild infection were easily treated, the two cases were post traumatic.

JAIN et al., 2002 concluded that, the allopathic substitutes had failed as a result of exposure and extrusion [5]. While Piero et al., 2000 mentioned that MEDPOR ${ }^{\circledR}$ is a porous alloplastic material and rarely become infected, when exposed will not be absorbed like cartilage [15]. Wellisz, 1993 reported five implant exposures, these were managed without removal of the implant, and all went on to heal uneventfully [12]. Sengezer et al., 1996 mentioned three exposures in 10 ear reconstruction cases which were managed without implant removal [18]. Reinisch et al. 2009 reported 7\% exposure rate in ear reconstruction using Porous polyethylene framework was performed on 786 cars over an 18-year period [19]. Zhao et al. 2009 reported that exposure of frame were 15 $(1.07 \%)$ in 1485 autogenous graft cases autogenous graft while occurred in $48(13.5 \%)$ cases MEDPOR ${ }^{\circledR}$ alloplastic frame [9]. In this article there was one case of early exposure and the mesh was removed, we avoid exposure of the mesh by wide enough pocket (tension free closure) in the $1^{\text {st }}$ stage and deeper dissection for projection in the $2^{\text {nd }}$ stage.

Donor site morbidity related to harvest of the rib cartilage includes the risk of pneumothorax, significant initial postoperative pain, resulting thorax scarring and a visible chest wall deformity in most patients [20], all these complications were avoided by use of alloplastic frame.

Hospitalization time is significantly shorter. There is less surgical intervention and the patient is spared the additional procedure needed for harvesting and carving the rib cartilage [14].

Some absorption of the rib cartilage may occur [9], so when used cartilage framework, it is made thicker than normal ear cartilage in order to hold its shape, projection and details beneath the overlying skin [21]. While the long-term follow-ups showed that the porous polyethylene framework had no deformation. The contour of auricular prosthesis was vivid and stable [22].

It is basically important the quality and quantity of the skin available for framework coverage [10]. The post auricular skin may be considered a flap bank for reconstruction; it has great vascularity, and has similar skin texture and color [23].

When alloplastic materials are used subcutaneously, there is definite risk of skin breakdown, contamination and eventually the loss of entire reconstructive procedure [8]. The reconstruction must start by placing the framework in an ideal position under unscarred skin [11]. Wellisz, 1993 said that no complications were associated with any of the implants placed in deep tissue pockets in 41 cases of ear reconstruction [12].

When the postauricular skin is scarred due to trauma or infection there is no sufficient skin available to cover the framework [9]. In this article that was the cause of failure in one case due to traumatized postauricular skin.

The age of he patient should be considered, costal cartilage will calcify as age advances, it will certainly calcify at age of 30 years, calcification of costal cartilage make carving more difficult and fractures more common [9]. The alloplastic implant does not grow with body and their use is restricted to adults [9]. In addition, this agrees also with the Polypropylene mesh.

\section{Conclusion}

Finally the polypropylene mesh framework is a simple technique, with satisfactory clinical results, easily done, even under local anesthesia, with no donor site morbidity of autogenous cartilage harvesting, not costly as other alloplastic substitutes, large series and longer follow up period are needed for better evaluation of this technique.

\section{REFERENCES}

[1] B. Brent, "The Acquired Auricular Deformity, a Systemic Approach to Its Analysis and Reconstruction,” Plastic and Reconstructive Surgery, Vol. 59, No. 4, 1977, pp. 475-485. doi:10.1097/00006534-197704000-00001

[2] E. Anesti, R. Karoo and A. Phipps, "Auricular Reconstruction with the Use of a Modified Rhomboid Flaps," European Journal of Plastic Surgery, Vol. 33, No. 5, 2010, pp. 311-313. doi:10.1007/s00238-010-0501-x

[3] R. Bernd, "Reconstruction of the External Ear after Trauma or Tumor Surgery, Master Class in Plastic Surgery,” European Journal of Plastic Surgery, Vol. 28, No. 1, 2005, pp. 7-16.

[4] G. Ellabbam, M. I. Maamoun and M. Elsharkawi, “The Bi-Pedicle Post-Auricular Tube Flap for Reconstruction of Partial Ear Defects," British Journal of Plastic Surgeons, Vol. 56, No. 6, 2003, pp. 593-598. 


\section{doi:10.1016/S0007-1226(03)00222-4}

[5] S. Jain, P. Kumar and L. M. Bariar, "Total Auricular Reconstruction with Autogenous Costal Cartilage Framework for Congenital Microtia (Grade-III)," Indian Journal of Otolaryngology and Head and Neck Surgery, Vol. 54, 2002, p. 3.

[6] G. Osorno, "A 20-Year Experience with the Brent Technique of Auricular Reconstruction: Pearls and Pitfalls," Plastic and Reconstructive Surgery, Vol. 119, No. 5, 2007, pp. 1447-1463.

doi:10.1097/01.prs.0000258572.57161.d8

[7] R. L. Walton and E. K. Beahm, “Auricular Reconstruction for Microtia,” In: M. Z. Siemionow and M. Eisenmann-Klein, Eds., Plastic and Reconstructive Surgery, Springer-Verlag, London, 2010.

[8] H. Fischer, W. Gubisch and V. Sinha, "Auricular Reconstruction-Our Experience at Marine Hospital Stuttgart, Germany, Original Article,” Indian Journal of Otolaryngology and Head \& Neck Surgery, Vol. 62, No. 2, 2010, pp. 162-167.

[9] Y. Zhao, Y. Wang, H. Zhuang, et al., "Clinical Evaluation of Three Total Ear Reconstruction Methods,” Journal of Plastic, Reconstructive \& Aesthetic Surgery, Vol. 62, No. 12, 2009, pp. 1550-1554. doi:10.1016/j.bjps.2008.07.009

[10] P. S. Bhandari, "Total Ear Reconstruction in Post Burn Deformity,” Burns, Vol. 24, No. 7, 1998, pp. 661-670. doi:10.1016/S0305-4179(98)00093-X

[11] B. Brent, "Auricular Repair with Autogenous Rib Cartilage: Two Decades Experience with 600 Cases,” Plastic and Reconstructive Surgery, Vol. 90, No. 3, 1992, pp. 355-373. doi:10.1097/00006534-199209000-00001

[12] T. Wellisz, "Clinical Experience with the Medpor Porous Polyethylene Implant Aesth,” Aesthetic Plastic Surgery, Vol. 17, No. 43, 1993, pp. 339-344. doi:10.1007/BF00437109

[13] S. Ohmori, "Reconstruction of Microtia Using the Silastic Frame," Clinics in Plastic Surgery, Vol. 5, No. 3, 1978, pp. 379-387.

[14] A. Berghaus, et al., "Ear reconstruction with porous poly- ethylene implants,” Adv Otorhinolaryngol, Vol. 68, 2010, pp. 53-64. doi:10.1159/000314562

[15] J. L. Piero Ibanez, et al., “Auricular Alloplastic Reconstruction with Osteointegrated Implants, a New Therapy Option in Microtia,” Cir Pediatr Journal, Vol. 13, 2000, pp. 25-29.

[16] T. Romo, M. S. Fozo and A. P. Sclafani, "Microtia Reconstruction Using a Porous Polyethylene Framework," Facial Plastic Surgery, Vol. 16, No. 1, 2000, pp. 15-22. doi:10.1055/s-2000-7322

[17] T. Wellisz, "The Reconstruction of the Burned External Ear Using a MEDPOR Porous Polyethylene Pivoting Helix Framework,” Plastic and Reconstructive Surgery, Vol. 91, No. 5, 1993, pp. 811-818. doi:10.1097/00006534-199304001-00009

[18] M. Sengezer, M. Turegun, S. Isik and M. Sezgin, "Reconstruction of the Microtic External Ear in Adults Using Porous Polyethylene Implant,” European Journal of Plastic Surgery, Vol. 19, No. 6, 1996, pp. 314-317. doi:10.1007/BF00180325

[19] J. F. Reinisch and S. Lewin, "Ear Reconstruction Using a Porous Polyethylene Framework and Temporoparietal Fascia Flap,” Facial Plastic Surgery, Vol. 25, No. 3, 2009, pp. 181-189. doi:10.1055/s-0029-1239448

[20] S. A. Zim, "Microtia Reconstruction: An Update,” Current Opinion in Otolaryngology \& Head and Neck Surgery, Vol. 11, No. 4, 2003, pp. 275-281. doi:10.1097/00020840-200308000-00011

[21] S. Nasser, "Improvement of the Aesthetic Outcome and Reduction of the Donor Site Morbidity in Autogenous Microtia Reconstruction, Egypt,” Plastic and Reconstructive Surgery, Vol. 33, No. 2, 2009, pp. 245-251.

[22] H. Y. Jiang, et al., "Surgical Treatment of Acquired Ear Defect Chinese Article,” Zhonghua Zheng Xing Wai Ke Za Zhi, Vol. 23, No. 2, 2007, pp. 106-108.

[23] A. Cordova, et al., "Retroauricular Skin: A Flaps Bank for Ear Reconstruction,” Journal of Plastic, Reconstructive \& Aesthetic Surgery, Vol. 61, Suppl. 1, 2008, pp. 4451. 